Australian Journal of

Crop Science

AJCS

AJCS 12(01):135-150 (2018)

ISSN:1835-2707

doi: 10.21475/ajcs.18.12.01.pne790

\title{
Agro-morphological characterization of diverse sorghum lines for pre-and post-flowering drought tolerance
}

\author{
Yves Emendack ${ }^{* 1}$, John Burke ${ }^{1}$, Jacob Sanchez ${ }^{1}$, Haydee Echevarria Laza ${ }^{2}$, Chad Hayes ${ }^{1}$ \\ ${ }^{1}$ Plant Stress and Germplasm Development Research Unit, Cropping Systems Research Laboratory, USDA-ARS, 3810, $4^{\text {th }}$ \\ Street, Lubbock, Texas, U.S.A. \\ ${ }^{2}$ Department of Plant and Soil Sciences, Texas Tech University, Lubbock, Texas, U.S.A.
}

*Corresponding author: Yves.Emendack@ars.usda.gov

\begin{abstract}
The impact of drought stress on sorghum yield does not only depend on the intensity and timing of drought, but as well on the developmental stage of the crop. One of the limitations in breeding for pre-and/or postflowering drought stress resistance in sorghum is the less availability of diverse genetic sources possessing drought tolerant agro-morphological or physiological traits that could be introgressed into elite sorghum lines. This research evaluate a diverse group of 54 introgressed, converted, and commonly used sorghum breeding lines for their tolerance to field drought stress imposed at the pre-flowering and post-anthesis developmental stages in 2015 and 2016 growing seasons. Agro-morphological characteristics such as panicle area, panicle width, and percent green leaf and yield-related characteristics such as total above ground dry biomass and dry panicle weight were identified as significant predictors of grain yield under water stress. The current research identifies other sources that could be use by breeding programs as donor lines for traits related to pre-and postflowering drought tolerance in sorghum. Following statistical distribution and Tukey-Krammer HSD connecting letter tests, lines JB39, SC191, and SC270 and RIL R.11269 were identified as plausible sources for pre-flowering drought tolerance, and JB14, JB15, JB19, JB22, JB24, JB25, JB26, and JB33 as sources for the staygreen trait. While the staygreen is a good selection tool for postflowering drought tolerance, identifying staygreen lines with minimal reductions in grain yield and with earlier flowering dates (JB14, JB22, JB24 and JB25 in this study) than most commonly used staygreen donor lines, will ensure that grain yield is not over sacrificed by the ability of the crop to staygreen under terminal drought conditions.
\end{abstract}

Keywords: Terminal drought; diverse; sorghum; senescence; staygreen; yield.

Abbreviations: BST_basal tiller; CTL_control; G_genotype; HGT_height; I_irrigation; NDT_nodal tiller; NGL_number of green leaves; NOL_number of leaves; PDL_peduncle length; PGL_percent green leaves; $p$ HI_panicle harvest index; PNL_panicle length; PNA_panicle area; PRF_pre-flowering; PSF_posrflowering; PWD_panicle width; PWT_panicle weight; S_status; SBM_straw biomass; TBM_total biomass.

Introduction

Sorghum (Sorghum bicolor L. Moench) is the fifth most important cereal crop cultivated worldwide. Sorghum is well adapted to drought environments compared to other cereals (Doggett, 1988; Ludlow and Muchow, 1990; Mullet et al., 2001; Sanchez et al., 2002 and Borrell et al., 2006), making it suitable for semi-arid tropical agricultural production systems. In parts of Africa and Southeast Asia, sorghum is an indigenous staple crop feeding millions of poor people. It is grown in agroecological zones with limited rainfall because of its drought tolerance, thus serving to combat food insecurity.

While drought stress affects sorghum crop growth and yield, the severity depends on the timing, the intensity of the stress, and the crop developmental stage. Sorghum crop growth and development is divided into three main stages, viz. GS1; growth stage 1 from planting to panicle initiation, GS2; growth stage 2 from panicle initiation to flowering, and GS3; growth stage 3 from flowering to physiological maturity (Zadoks et al., 1974; Rao et al., 2004). Drought stress at any of these stages can lead to significant yield losses (Tuinstra et al., 1997; Rosenow and Clark, 1995). However, there is a wide genetic diversity in the morphological, physiological, and agronomical response of sorghum to drought (Emendack 2007; Hamza et al., 2016). Two forms of drought stress have been identified in sorghum, viz. pre-anthesis (pre-flowering) drought stress; where plants experience moisture stress during panicle differentiation prior to flowering, and post-anthesis (postflowering) drought stress when moisture stress occurs during the grain filling stage (Rosenow and Clark, 1995). 
Pre-flowering drought stress in grain sorghum usually results in failure of grain production due to panicle blasting and ovary abortion. Post-anthesis drought stress can result in substantial yield losses from reduction in number of grains and poor grain filling. There are genotypes that show some post-flowering drought tolerance, a characteristic often referred to as staygreen. These genotypes maintain green leaf area and hence photosynthetic capability and/or improved translocation of carbohydrates under late season moisture stress, and produce higher grain yields compared with senescent genotypes (Borrell and Douglas, 1997; Borrell et al., 2003). Staygreen genotypes have also been shown to have a comparatively higher level of the secondary metabolite dhurrin (a Cyanogenic glucoside with nitrogen storage function) in leaves of matured plants at the late vegetative stage (Burke et al., 2013), and 10-day old seedlings of staygreen lines showed higher biomass than senescent lines under nitrogen limiting conditions (Emendack et al., 2016).

Plant response to drought stress is complex, reflecting over space and time the integration of stress effects and responses at all underlying levels of organization (Yordanov et al., 2003). A good understanding of factors limiting yield under drought requires an integrated evaluation of plant response, and identification of traits involve at the agronomic, morphological, physiological, and molecular levels. Agronomic and morphological traits were the earliest markers used to study genetic diversity in germplasm and they play important roles in determining yield. They have been used in breeding programs to improve yield and introduce commercial varieties under drought stress condition (Mollasadeghi et al., 2011). Genetic variability for agronomic, morphological, and physiological traits is a key component in breeding programs for broadening the gene pool and understanding the genetic basis of drought tolerance in crops (Mitra, 2001; Ahmad et al., 2011).

Many breeding programs in the United States extensively used sorghum germplasm from Ethiopia and Sudan as valuable source of genetic diversity for drought tolerance and resistance to numerous diseases (Prom and Erpelding, 2009; Cuevas et al., 2012, 2016; Upadahyaya et al., 2009). Though these are important centers for sorghum germplasm genetic variation, photoperiod sensitivity inherited with the vast majority of tropical germplasm accessions, place limitations on the utilization of this genetic resources as potential donors of genes for the development of new abiotic or biotic stress tolerant varieties. Additionally, most of the post-flowering drought tolerant lines developed in the U.S. and Australia arose from a single ancestor (B35, released as BTx642 by the Texas Agricultural Experiment Station in 2002, and was derived from the intentional cross [BTx406*IS12555F3)*IS12555]-6). Although it has become a standard post-flowering drought tolerant (staygreen) check in numerous studies, the delayed flowering and poor pre-flowering drought tolerance of BTx642 has limited its' incorporation into commercial breeding lines. The main goals of this study were to 1) identify agromorphological traits and yield components that are good predictors for grain yield under water stress condition and 2) identify alternative sources for integrating pre-and postflowering drought tolerance into commercial hybrids. The responses of these trait to water stress imposed before-or postflowering will be evaluated in characterizing resistance to drought stress in sorghum.

\section{Results}

\section{Weather patterns during growing seasons}

Precipitation distribution and seasonal daily temperature patterns differed between years (Fig. 1). Seasonal days from planting to harvest also varied between years: 112 days (day 5 to day 117) in 2015 experiment, and 126 days (day 1 to day 127) in 2016 experiment.

Precipitation distributions (spikes) were sporadic from planting till early mid-season: less so in 2015 (seasonal day 5 to 47) than in 2016 (seasonal day 1 to 52). From early mid-season onward, there were less sporadic precipitation scenarios in 2015 compared to 2016 growing season. Also in 2015, plants received additional $5 \mathrm{~mm}$ irrigation daily (except when stress was imposed) via subsurface drip. The three major spikes in 2016 precipitation line represent furrow irrigation applied at 30, 52, and 67 days after planting (DAP), with pre-flowering and postflowering stress imposed at 52DAP and 67DAP respectively. More sporadic precipitation events were observed in 2016 following the imposition of postflowering water stress. Daily temperature patterns revealed a cooler beginning (averaged $3-7^{\circ} \mathrm{C}$ dip) in the 2016 planting season compared to the 2015 planting season. Similar observations were made late mid-season (seasonal day 76 to 90), with average temperature differences of $3-5^{\circ} \mathrm{C}$ in favor of the 2015 growing season.

\section{Irrigation and precipitation}

The regional annual precipitation for West Texas ranges between $381 \mathrm{~mm}$ to $457 \mathrm{~mm}$, with an average of $254 \mathrm{~mm}$ occurring during sorghum growing season.

Under the control treatment (CTL), the amount of precipitation received in both growing seasons were similar viz. $155.0 \mathrm{~mm}$ in 2015 and 164.0mm in 2016 (Table 2). However, the total seasonal water applied (precipitation plus irrigation) in 2016 was only $51 \%$ (315.5 vs. $605.0 \mathrm{~mm}$ ) of the amount applied in 2015. Prior to imposing pre-flowering drought stress (PRF), the amount of water made available in 2016 was $56 \%$ that of 2015 ( $113.0 \mathrm{~mm}$ vs. $202.0 \mathrm{~mm}$ ), though the total seasonal water applied to the PRF treatment in 2016 was $73 \%$ ( 214.5 vs. $290.0 \mathrm{~mm}$ ) that of 2016 . Also, prior to imposing postflowering drought stress (PSF), the amount of water made available in 2016 was $42 \%$ (152.0mm vs. $365.0 \mathrm{~mm}$ ) that of 2015 , while the total seasonal water received by the 2016 PSF treatment was $72 \%$ (265.0 vs. $365.0 \mathrm{~mm}$ ) that of 2015 . Late rainfall in the 2016 season meant visual ratings for number of green leaves and thus percent green leaves were unreliable and not considered.

\section{Data visualization and analysis}

To explore the strong pattern, identify any variation in data set, and explain any variance or covariance in the assessed agro-morphological characteristics due to the different irrigation treatments, data set were pulled (with respect to 
treatments) from 2015 and 2016 and subjected to principal component analysis (PCA). Using scree plots, two components (factors) were retained from each treatment and later interpreted using varimax rotation (supplementary Table 2). The rotated solutions revealed the presence of simple structure in all irrigation treatment, with both components showing a number of strong loadings and all parameters loading substantially on only one component. The two components explained a total of $50.65 \%$ (component 1; $25.60 \%$ and component $2 ; 25.05 \%$ ), $47.13 \%$ (component 1; $24.45 \%$ and component $2 ; 22.68 \%$ ), and $51.44 \%$ (component 1 ; $30.43 \%$ and component $2 ; 21.01 \%$ ) of the variance in the control, pre-flowering, and post flowering irrigation treatments respectively. Generally, panicle area, panicle weight, panicle width, and total biomass had positive affect in explaining the total variance observed across treatments. Factor loading plots and score plots with imputations (supplementary figure 2) showed stronger patterns and distribution of parameters under pre-and postflowering drought treatments than under the control treatment.

Observed variations in agro-morphological characteristics based on the treatments and their interactive effects were expressed in percentage as a proportion of variance (Table 3 ). Effects were ranked small $\left(\eta^{2} \leq 1 \%\right)$, medium $\left(1 \leq \eta^{2} \leq 6 \%\right)$, and large $\eta^{2} \geq 14 \%$. Variability in all assessed characteristics was largely due to genotypic differences, with proportions ranging from $20.3 \%$ for number of nodal (asynchronous) tillers, to $88.0 \%$ in peduncle length (exertion). All yield-related components showed higher proportion (panicle weight; 38\%; shoot biomass, $24.2 \%$, total biomass, $50.1 \%$, and panicle harvest index, $48.7 \%$ ) of variation coming from genotypic differences. Interactive effects of genotype and irrigation were mostly medium in proportion (except in number of green leaves and percent green leaves), ranging from $6.0 \%$ in height to $11.4 \%$ in number of leaves.

The proportion of the effect of status (common breeding lines vs. introgress lines vs. converted lines) on assessed characteristics were medium for the morphological characters; number of green leaves (8.2\%), percent green leaves (8.7\%), panicle width $(7.8 \%)$ and panicle area $(9.0 \%)$, and large for exertion (15.0\%), but insignificant for all yield-related components (SBM, TBM, PWT, and $\mathrm{pHI}$ ). Also, the proportions of the effect of irrigation were medium for yield-related components (SDM, 8.1\%, TBM, 10.4\%; and PWT, 6.6\%) and morphological characters panicle width and panicle area.

\section{Morphological characteristics}

In both years, the variation due to irrigation was strongest on panicle width and panicle area; with highest values observed under the control irrigation treatment, followed by the postflowering irrigation treatment, and then the pre-flowering irrigation treatment (Table 4). Values for both characteristics were comparatively higher in 2015 than in 2016 irrespective of irrigation treatment. However reductions in both characteristics from 2015 to 2016 were strongest under the control irrigation treatment (PNW, 24\% and PNA, 27\%). Values for most of the other morphological characteristics were highest under control irrigation treatment in both years, with the pre-flowering and postflowering values showing no significant difference. In 2015, the staygreen characteristics NGL and PGL were highest under the control irrigation treatment, followed by postflowering, and then pre-flowering irrigation treatments. Compared to the control, percent green leaf was reduced by $57 \%$ and $32 \%$ under pre-flowering and postflowering irrigation treatments respectively.

Genotypic distribution of PNW and PNA into quantiles showed some consistencies in both years for lines in the 75\%quartiles across irrigation treatments.

In 2015 (Fig. 2), rank order for panicle width in the 75\% quartiles for the three irrigation treatments were: 1) CTL irrigation (Fig. 2A, PWD $\geq 5.5 \mathrm{~cm}$ ); JB44, JB37, JB30, SC847, SC191, JB35, JB33, and JB25, 2) PRF irrigation (Fig. 2B; $P W D \geq 4.0 \mathrm{~cm}) ; \mathrm{SC} 847, \mathrm{JB} 42, \mathrm{SC} 191, \mathrm{JB} 30, \mathrm{Ib} 37, \mathrm{JB} 44, \mathrm{JB} 24$, and JB31, and 3) PSF irrigation (Fig. 2C, PWD $\geq 4.5 \mathrm{~cm}$ ); JB44, JB31, JB30, SC847, JB24, JB37, JB43, and JB18.

Rank order for panicle area in the $75 \%$ quartile were: 1) CTL irrigation (Fig. 2A; $P N A \geq 132 \mathrm{~cm}^{2}$ ); JB31, JB35, JB33, JB22, JB18, $J B 44, J B 17, J B 42$, and JB32, 2) PRF irrigation (Fig. 2B; $P N A \geq 91 \mathrm{~cm}^{2}$ ); JB31, JB42, JB14, JB17, SC191, JB30, and JB22, and 3) PSF irrigation (Fig. 2C; $P N A \geq 104 \mathrm{~cm}^{2}$ ); JB31, JB18, JB44, JB35, and JB17.

In 2016 (Fig. 3), lines in the 75\% quartiles for panicle width under the different irrigation treatments ranked as follows: 1 ) Control irrigation (Fig. 3A; PWD $\geq 4.5 \mathrm{~cm}$ ); JB31, JB44, TX7000, SC191, BTx3042, and JB24, 2) PRF irrigation (Fig. 3B; $P W D \geq 4.0 \mathrm{~cm}$ ); BTx378, BTx3042, JB39, SC191, JB22, 1790E, and R.11269, 3) PSF irrigation (Fig. 3C; PWD $\geq 4.0 \mathrm{~cm}$ ); B1778, JB31, JB25, BTx3042, TX7000, JB44, SC191, JB24, and R.11269.

Lines in the $75 \%$ quartile for panicle area under the three irrigation treatments were ranked as follows: 1) CTL irrigation (Fig. 3A; PNA $\geq 108 \mathrm{~cm}^{2}$ ); JB31, 1790E, TX7000, JB22, R.11259, BTx3042, SC191, JB44, and SC270, 2) PRF irrigation (Fig. 3B; $P N A \geq 96 \mathrm{~cm}^{2}$ ); 1790E, SC270, JB39, R.11269, and BTx3042, and 3) PSF irrigation (Fig. 3C; PNA $\geq 104 \mathrm{~cm}^{2}$ ); B1778 and JB31.

\section{Yield-related characteristics}

In both years, the variation due to irrigation was strongest on panicle weight (PWT) and total above ground dry biomass, with highest values observed under the control irrigation treatment, followed by the postflowering irrigation treatment, and then the pre-flowering irrigation treatment (Table 5). Panicles were comparatively heavier in 2015 than in 2016 irrespective of irrigation treatment. However reductions in PWT from 2015 to 2016 were strongest under pre-and postflowering irrigation treatments $(55 \%$ and $52 \%$ respectively) compared to $46 \%$ under control irrigation treatment. Total dried biomass was higher in 2015 than 2016 irrespective of irrigation treatment. Reduction in TBM was least under postflowering (41\%) compared to Pre-flowering and control ( $47 \%$ and $49 \%$ respectively) irrigation treatments. Panicle harvest indices showed a reversed rank order between control and water stress irrigation treatments from 2015 to 2016. In 2015, the value for $\mathrm{pHI}$ was significantly higher for the control treatment than in the pre-and postflowering treatments. The pre-and postflowering irrigation treatments were not significantly different in pHI. However, in 2016, the 


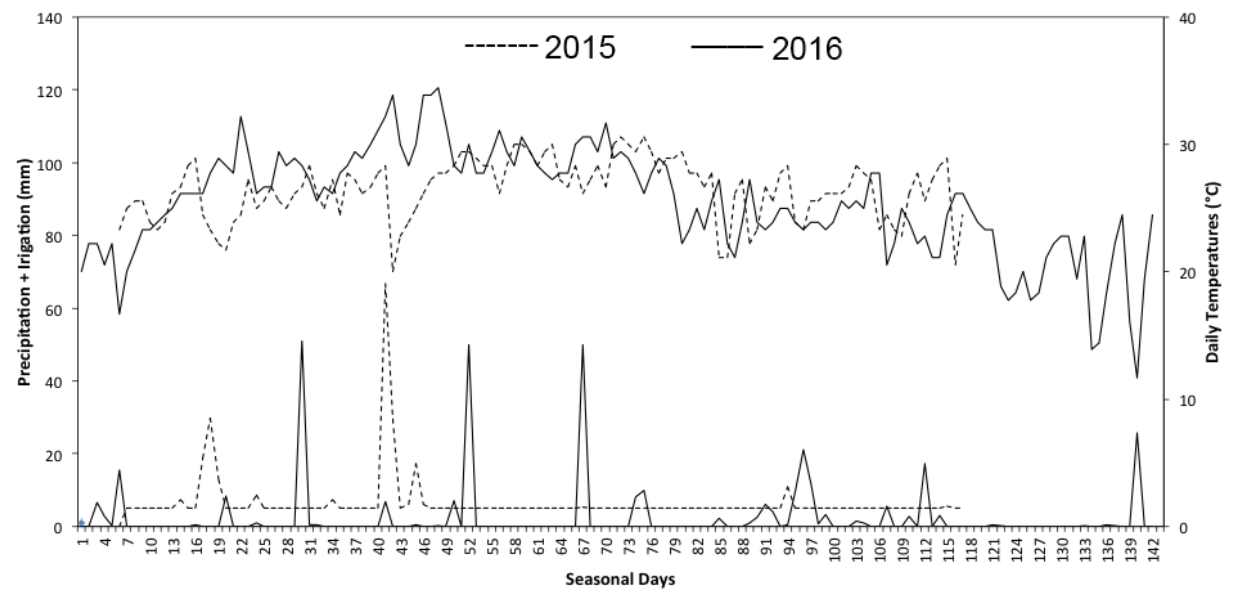

Fig 1. Two years precipitation plus irrigation distribution and daily temperature variation patterns (dashed lines for 2015 and full lines for 2016 seasons) for sorghum crop grown under three irrigation treatments in Texas.
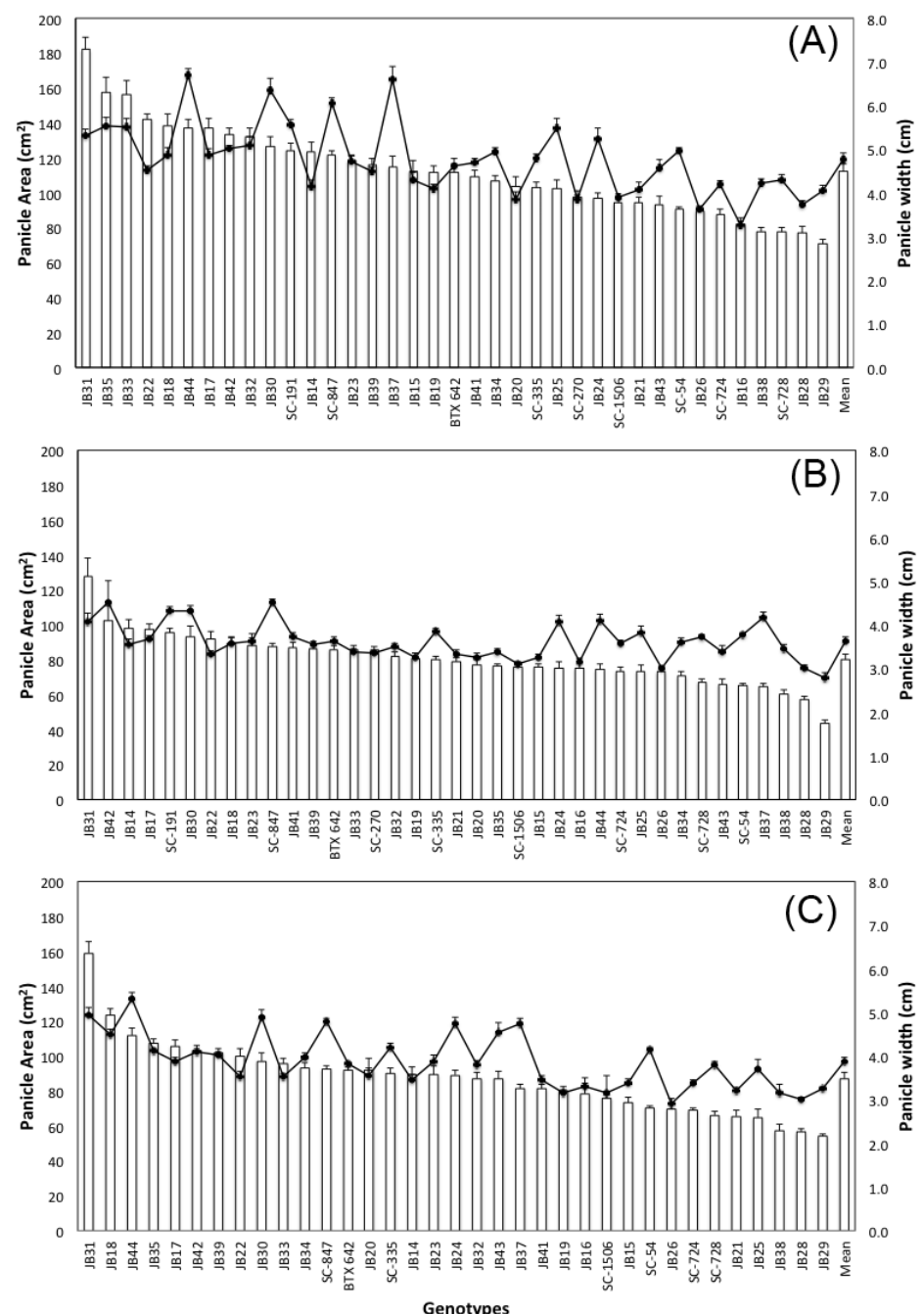

Fig 2. Variation of panicle width (line) and panicle area (bars) for diverse sorghum lines under control (A), pre-flowering (B), and post-flowering (C) irrigation in 2015 season. 
Table 1. Diverse sorghum lines agro-morphologically characterized for pre-and postflowering drought tolerance at two locations in Texas.

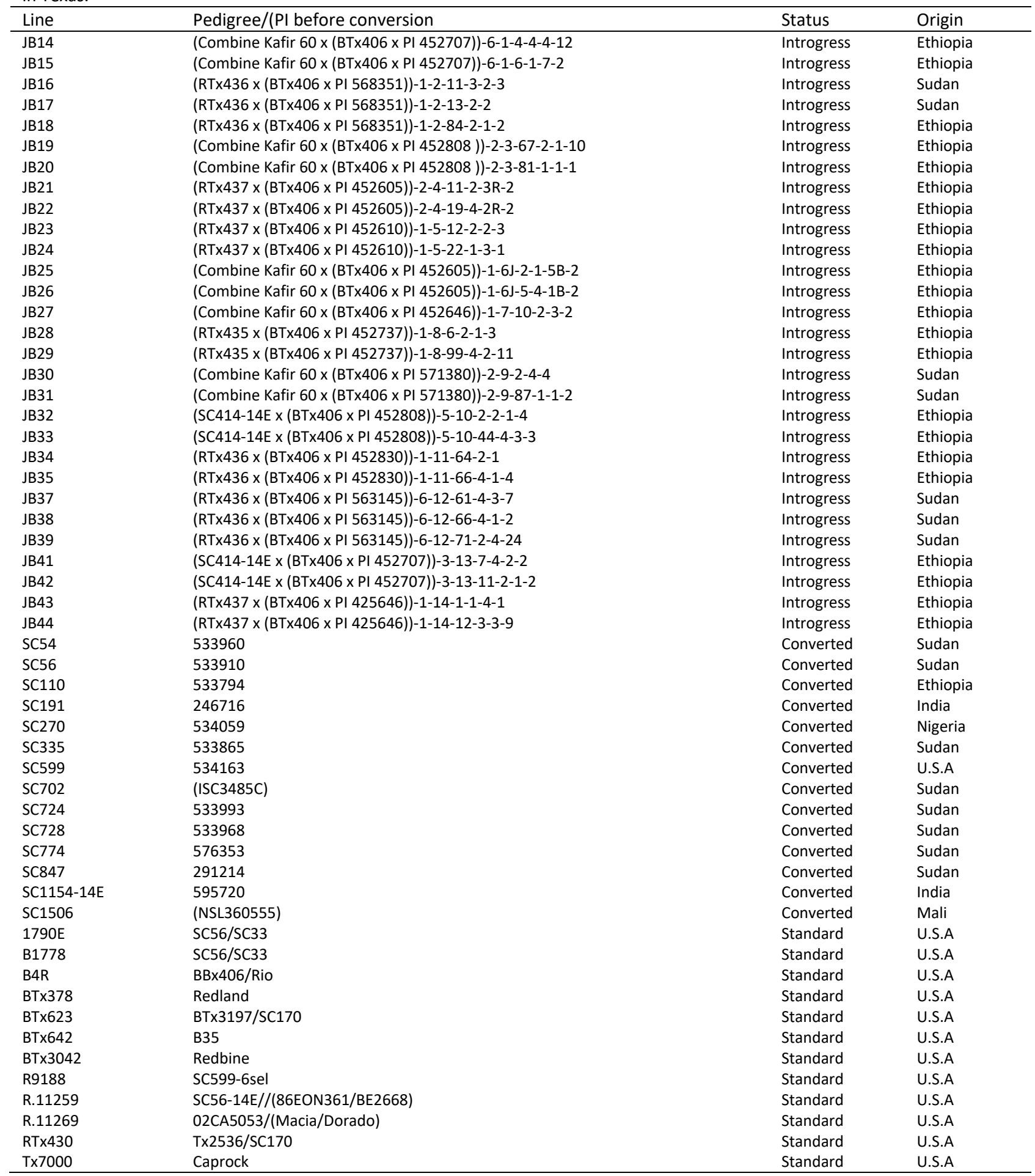


Table 2. Distribution of irrigation application plus precipitation $(\mathrm{mm})$ for field grown diverse sorghum lines in the 2015 and 2016 growing season.

\begin{tabular}{lllllll}
\hline & \multicolumn{2}{l}{ Control Irrigation } & \multicolumn{2}{l}{ Pre-flowering Irrigation } & \multicolumn{3}{l}{ Postflowering Irrigation } \\
& 2015 & 2016 & 2015 & 2016 & 2015 & 2016 \\
\hline Day planted & ${ }^{\mp} 5$ & 1 & 5 & 47 & 5 & 1 \\
Day irri. withheld & NA & NA & 47 & 52 & 62 & 67 \\
Irrigation amount & 460.0 & 151.5 & 135.0 & 50.5 & 210.0 & 101.0 \\
Pres. amount & 155.0 & 164.0 & 155.0 & 164.0 & 155.0 & 164.0 \\
\hline Total & 605.0 & 315.5 & 290.0 & 214.5 & 365.0 & 265.0 \\
\hline
\end{tabular}

${ }^{7}$ Seasonal days in figure 1; NA; data not applicable.
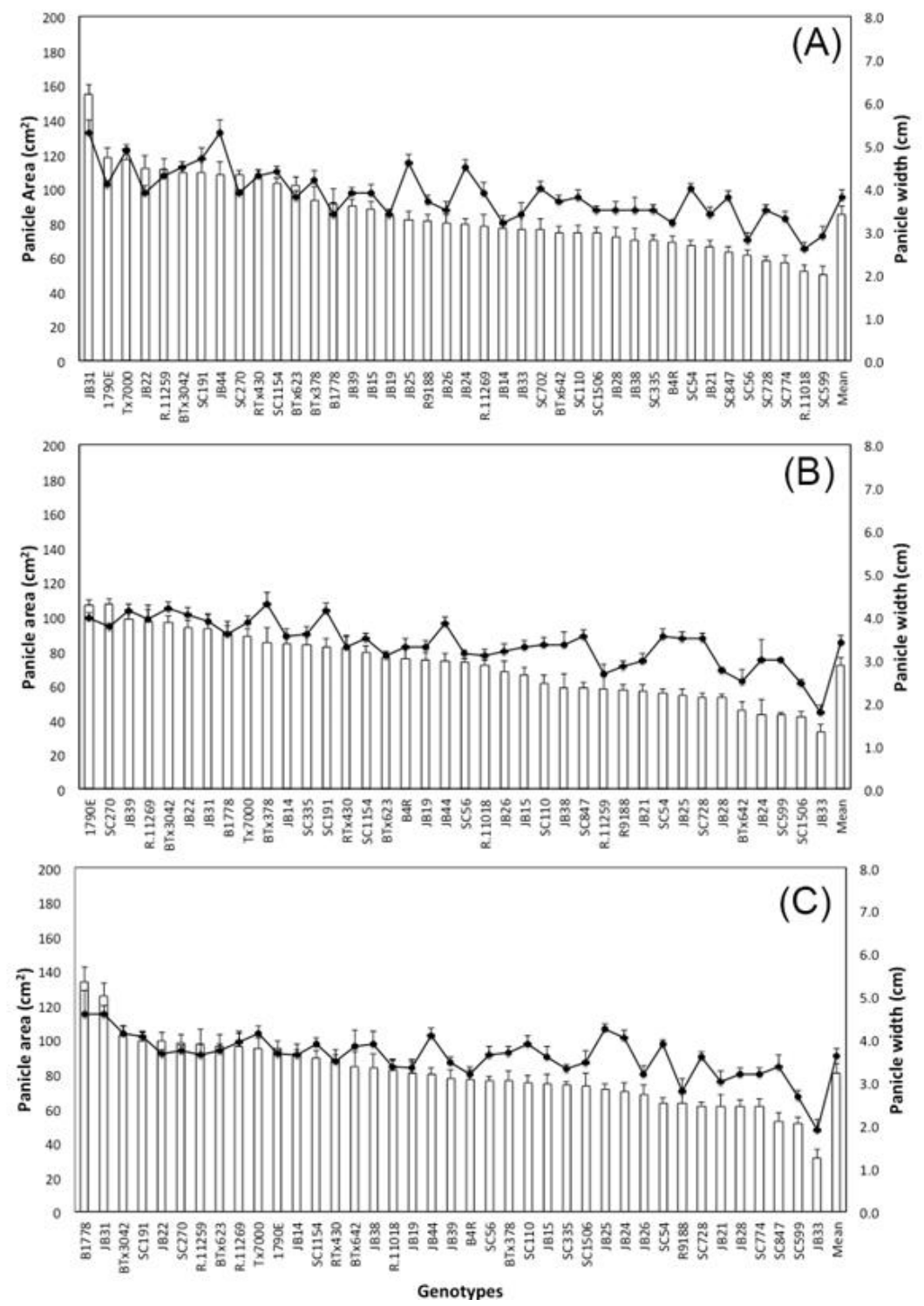

Fig 3. Variation of panicle width (line) and panicle area (bars) for diverse sorghum lines under control (A), pre-flowering (B), and post-flowering (C) irrigation in 2016 season. 
Table 3. Partial Eta squared $\left(\eta^{2}\right)$ values for multivariate interaction effects of irrigation (I), status (S) and genotype (G) on agromorphological characteristics. Values are averaged across both years and expressed in percentages as proportion of variance in the assessed characteristics explained by the treatments (I, S, or G).

\begin{tabular}{|c|c|c|c|c|c|c|c|c|c|c|c|c|c|c|c|}
\hline & NOL & NGL & PGL & BST & NDT & HGT & SDM & $\begin{array}{c}\text { PDL } \\
\mathrm{cm}--\end{array}$ & PNL & PWD & $\begin{array}{l}\text { PNA } \\
\left(\mathrm{cm}^{2}\right)\end{array}$ & PWT & SBM & TBM & $\mathrm{pHI}$ \\
\hline${ }^{\dagger} 1$ & - & - & - & - & - & - & - & - & - & 7.8 & 9.2 & 6.6 & 8.1 & 10.4 & - \\
\hline$S$ & & 8.2 & 8.7 & - & - & - & - & - & 15.0 & - & 9.0 & - & - & - & - \\
\hline $\begin{array}{l}G \\
I^{*} S\end{array}$ & 79.2 & 58.5 & 46.2 & 26.5 & 20.3 & 66.7 & 35.3 & 99.0 & 63.8 & 21.6 & 27.0 & 38.0 & 24.4 & 50.1 & 48.7 \\
\hline$I^{*} G$ & 11.4 & 31.0 & 25.5 & 7.4 & 10.5 & 6.0 & 6.8 & 8.9 & 9.0 & 7.9 & 8.1 & 7.8 & - & 8.4 & 10.3 \\
\hline $\mathrm{S}^{*} \mathrm{G}$ & - & - & - & - & - & - & - & - & - & - & - & - & - & - & - \\
\hline I*S*G & - & - & - & - & - & - & - & - & - & - & - & - & - & - & - \\
\hline Means & 13.7 & 4.4 & 32.7 & 0.6 & 0.3 & 116.1 & 1.8 & 5.1 & 22.6 & 4.0 & 91.8 & 57.9 & 43.2 & 110.5 & 0.53 \\
\hline$S E$ & 0.03 & 0.05 & 0.36 & 0.02 & 0.01 & 0.64 & 0.01 & 0.11 & 0.08 & 0.21 & 0.70 & 0.47 & 0.49 & 0.91 & 0.01 \\
\hline
\end{tabular}

FI, Irrigation; S, status of genotype (converted, introgress or standard breeding lines); G, genotype; NOL, number of fully developed leaves; NGL, number of green leaves; PGL, percent green leaves; BST, number of basal tillers; NDT, number of nodal tillers; HGT, height; SDM, stem diameter; PDL, peduncle length; PNL, panicle length; PWD, panicle width; PNA, panicle area; PWT, panicle weight; SBM, straw biomass; TBM, total biomass; and pHI, panicle harvest index. SE is the standard error of means. "-" Indicate proportion of effect was small ( $\left.\eta^{2} \leq 1 \%\right)$.
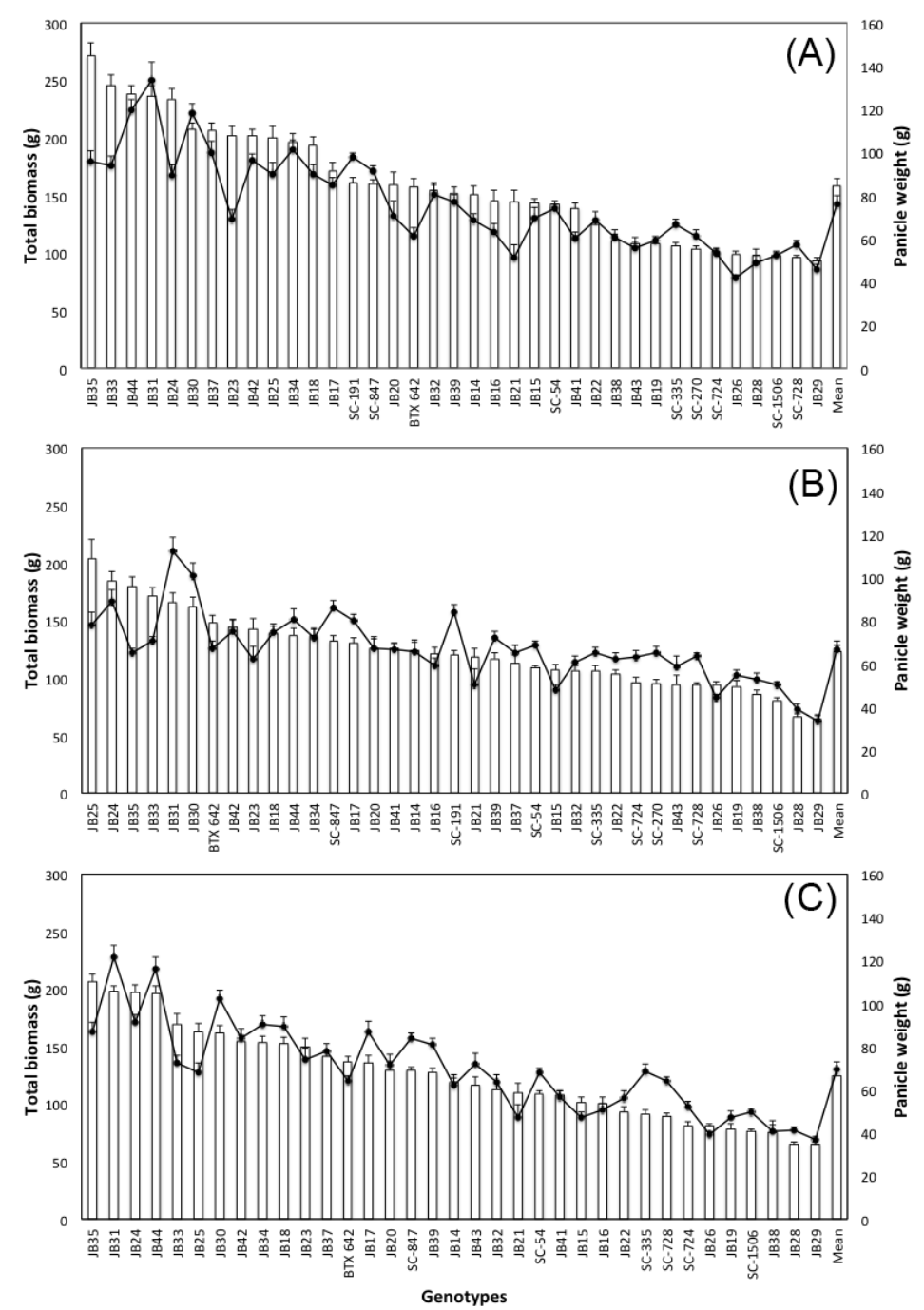

Fig 4. Variation of total biomass (bar) and panicle weight (line) for diverse sorghum lines under control (A), pre-flowering (B), and post-flowering (C) irrigation in 2015. 
Table 4. Variation of morphological characteristics of diverse sorghum lines subjected to three irrigation (IRR) treatments (CTL, control irrigation; PRF; pre-flowering irrigation; and PSF, postflowering irrigation) for two different years.

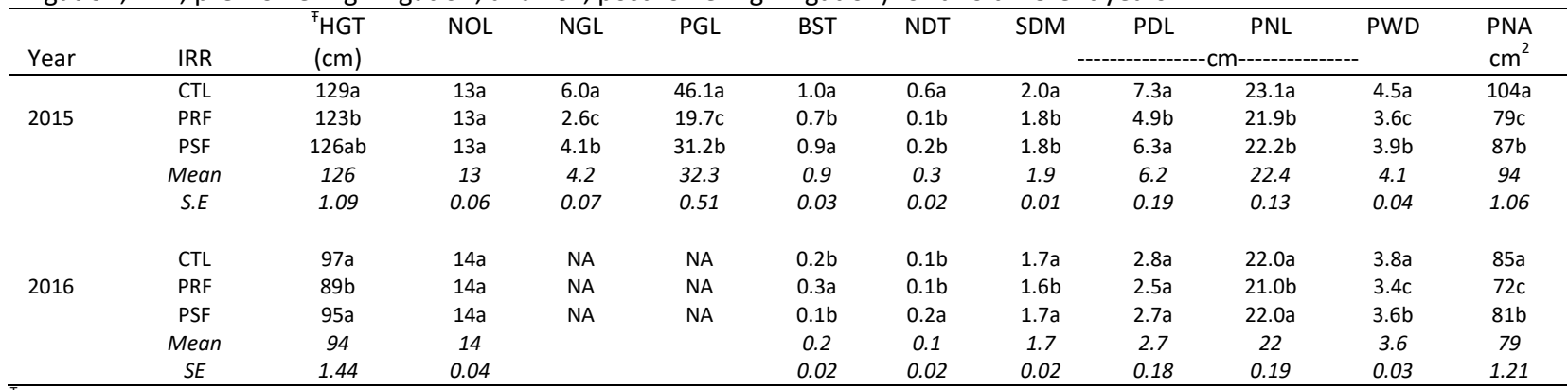

${ }^{\mp}$ HGT, plant height; NOL, number of leaves; NGL, number of green leaves; PGL, percent green leaves; BST, basal tillers; NDT, nodal tillers; SDM, stem diameter; PDL; peduncle length; PNL, panicle length; PWD, panicle width; PNA, panicle area. SE is standard error of means. N=1200. Values for irrigation treatments with the same letter(s) under a given characteristic are not significantly different, $p \leq 0.05$.
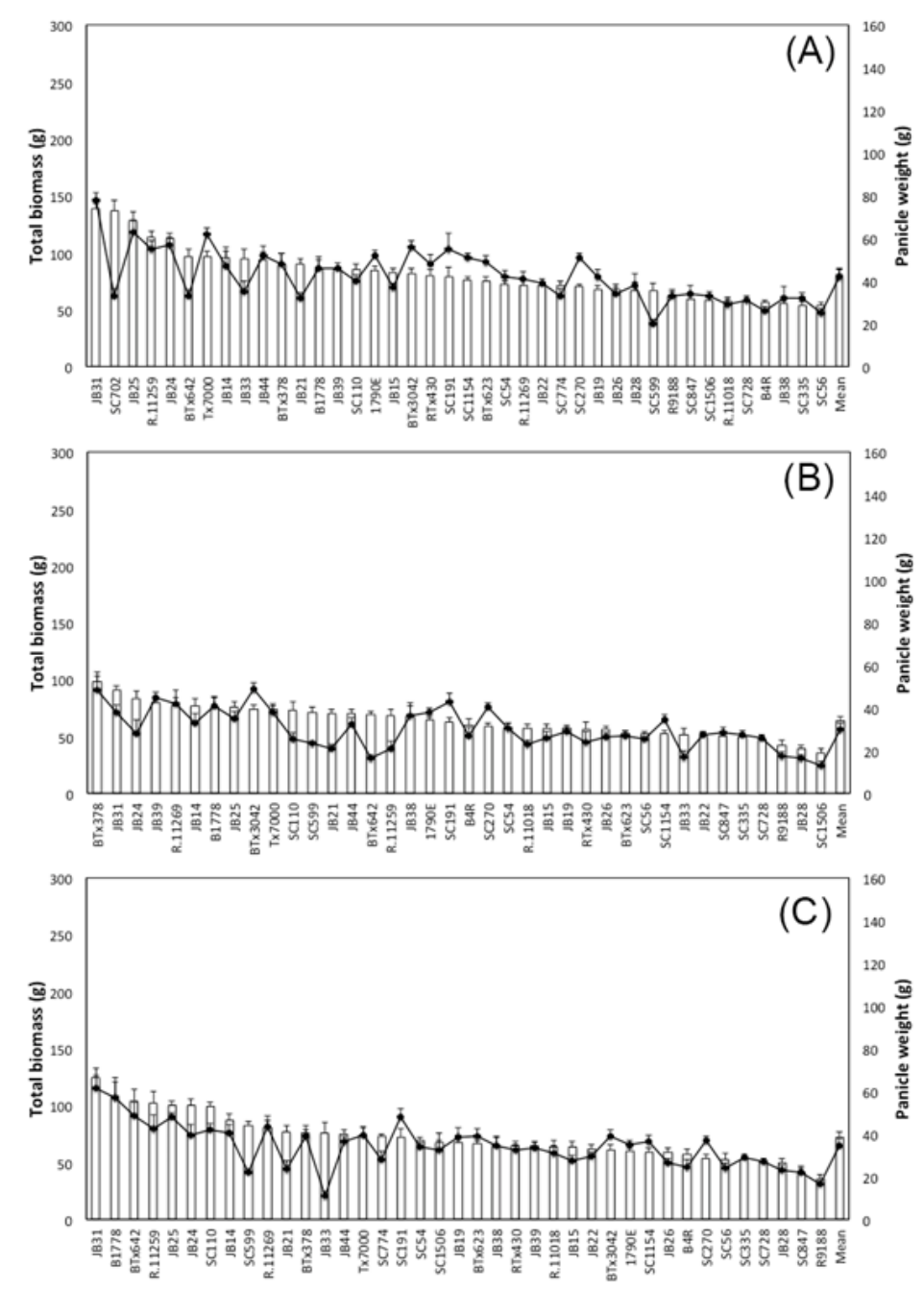

Fig 5. Variation of total biomass (bars) and panicle weight (lines) for diverse sorghum lines under control (A), pre-flowering (B), and postflowering (C) irrigation in 2016. 
Table 5. Variation of yield-related characteristics of diverse sorghum lines subjected to three irrigation (I) treatments (CTL, control irrigation; PRF; pre-flowering irrigation; and PSF, postflowering irrigation) in two different years.

\begin{tabular}{|c|c|c|c|c|c|c|c|}
\hline Year & 1 & ${ }^{\mathrm{F}} \mathrm{SBM}$ & TBM & PWT & $\mathrm{pHI}$ & NGL & PGL \\
\hline \multirow{4}{*}{2015} & CTL & NA & $158.3 a$ & $77.9 a$ & $0.50 \mathrm{~b}$ & $6.3 a$ & $46.1 a$ \\
\hline & PRF & NA & $119.8 \mathrm{~b}$ & $67.4 \mathrm{c}$ & $0.57 a$ & $2.7 c$ & $19.8 \mathrm{c}$ \\
\hline & PSF & NA & $122.5 b$ & $70.6 b$ & $0.58 a$ & $4.2 b$ & $31.3 \mathrm{~b}$ \\
\hline & Mean & & 133.7 & 72.0 & 0.55 & 4.4 & 32.7 \\
\hline \multirow{6}{*}{2016} & S.E & & 1.58 & 0.83 & 0.03 & 0.05 & 0.36 \\
\hline & CTL & $39.3 a$ & 81.3a & $42.1 \mathrm{a}$ & $0.52 \mathrm{a}$ & NA & NA \\
\hline & PRF & $33.4 a$ & $63.2 \mathrm{c}$ & $30.3 c$ & $0.46 \mathrm{~b}$ & NA & NA \\
\hline & PSF & $37.1 \mathrm{a}$ & $72.4 b$ & $34.2 b$ & $0.48 b$ & NA & NA \\
\hline & Mean & 36.6 & 72.3 & 35.5 & 0.48 & & \\
\hline & SE & 0.64 & 1.05 & 0.67 & 0.02 & & \\
\hline
\end{tabular}

${ }^{\mathrm{F}} \mathrm{SBM}$, straw dry biomass; TBM, total above ground dry biomass; PWT, panicle weight; $\mathrm{pHI}$, panicle harvest index; NGL, number of green leaves; PGL, percent green leaves. SE is standard error of means. $\mathrm{N}=1200$. Values for irrigation treatments with the same letter(s) under a given characteristic are not significantly different, $p \leq 0.05$.
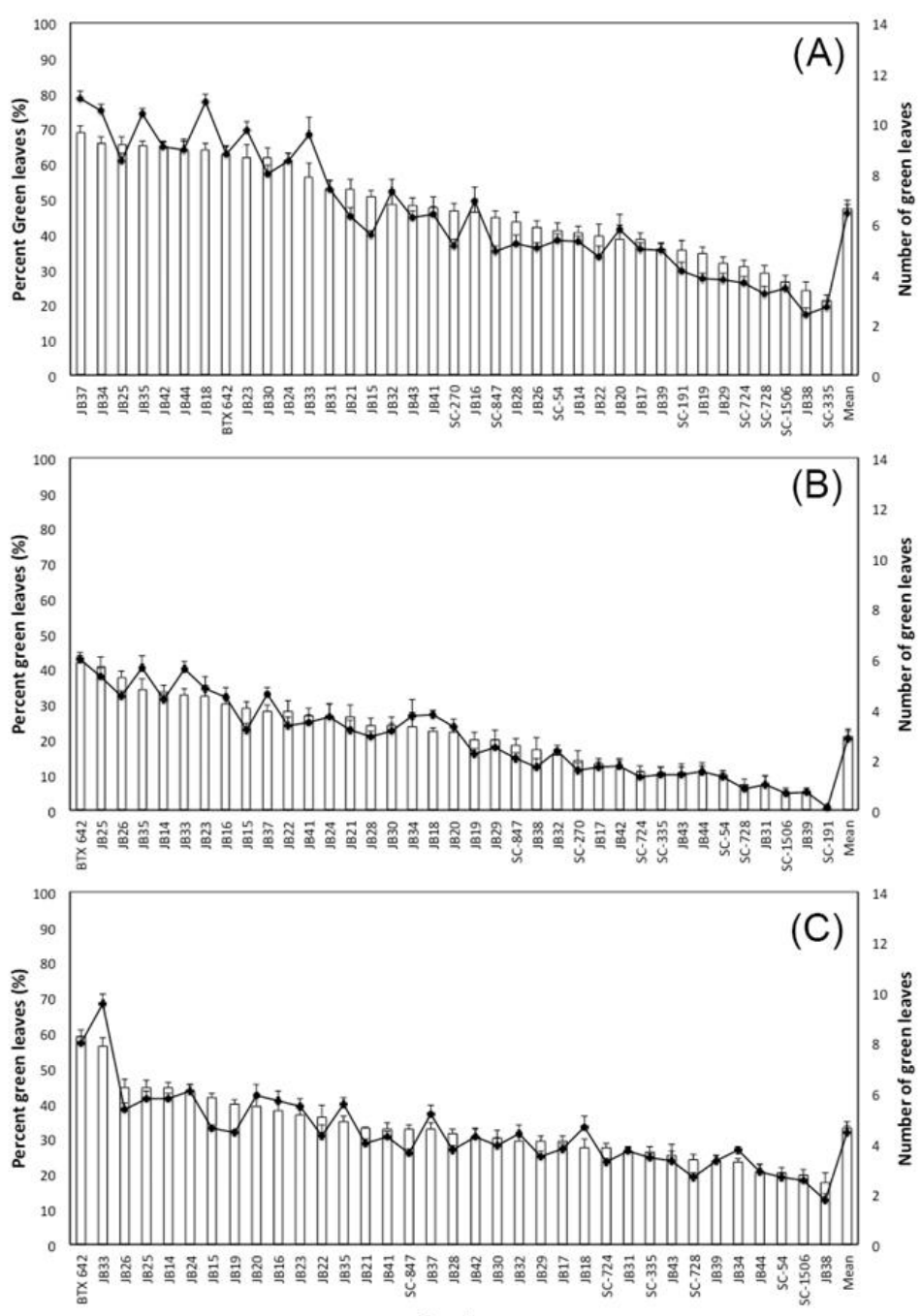

Fig 6. Variation of percent green leaves (bars) and number of green leaves (line) for diverse sorghum lines under control (A), preflowering (B), and postflowering (C) irrigation in 2015. 
Table 6. Significant Pearson correlations between agro-morphological traits for diverse sorghum lines subjected to three irrigation schedules (Control; CTL, Pre-flowering; PRF, and Postflowering; PSF) for two years.

\begin{tabular}{|c|c|c|c|c|c|c|}
\hline \multirow{2}{*}{$\begin{array}{l}\text { Panicle } \\
\text { Weight (g) }\end{array}$} & \multicolumn{3}{|c|}{2015} & \multicolumn{3}{|c|}{2016} \\
\hline & CTL & PRF & PSF & CTL & PRF & PSF \\
\hline${ }^{\mathrm{F}}$ TBM & 0.84 & 0.75 & 0.80 & 0.83 & 0.80 & 0.83 \\
\hline SBM & NA & NA & NA & 0.34 & 0.19 & 0.38 \\
\hline pHI & 0.29 & 0.33 & 0.35 & 0.35 & 0.69 & 0.53 \\
\hline PGL & 0.46 & NS & NS & NA & NA & NA \\
\hline NGL & 0.50 & NS & NS & NA & NA & NA \\
\hline PNL & 0.18 & 0.28 & 0.29 & 0.45 & 0.37 & 0.50 \\
\hline PWD & 0.77 & 0.76 & 0.76 & 0.77 & 0.82 & 0.80 \\
\hline PNA & 0.72 & 0.72 & 0.76 & 0.75 & 0.74 & 0.81 \\
\hline PDL & -0.13 & -0.19 & -0.15 & -0.13 & NS & NS \\
\hline SDM & 0.37 & 0.39 & 0.45 & 0.33 & 0.23 & 0.42 \\
\hline NOL & 0.40 & 0.19 & 0.32 & NS & -0.18 & ns \\
\hline HGT & 0.33 & 0.19 & 0.28 & 0.34 & 0.19 & 0.28 \\
\hline BST & NS & NS & NS & NS & NS & NS \\
\hline NDT & 0.19 & NS & NS & NS & -0.16 & -0.15 \\
\hline
\end{tabular}

${ }^{\mathrm{F}} \mathrm{TBM}$, total above ground biomass; SBM, above ground straw biomass; $\mathrm{pHI}$, panicle harvest index; PGL, percent green leaves; NGL, number of green leaves; PNL, panicle length; PWD, panicle width; PNA, panicle area; PDL, peduncle length; SDM, stem diameter; NOL, number of leaves; HGT, height; BST, basal tillers; and NDT, nodal tillers. "NS" not significant at $p \leq 0.05 ; \mathrm{N}=1200$ and 600 in 2015 and 2016 respectively, NA, not available.

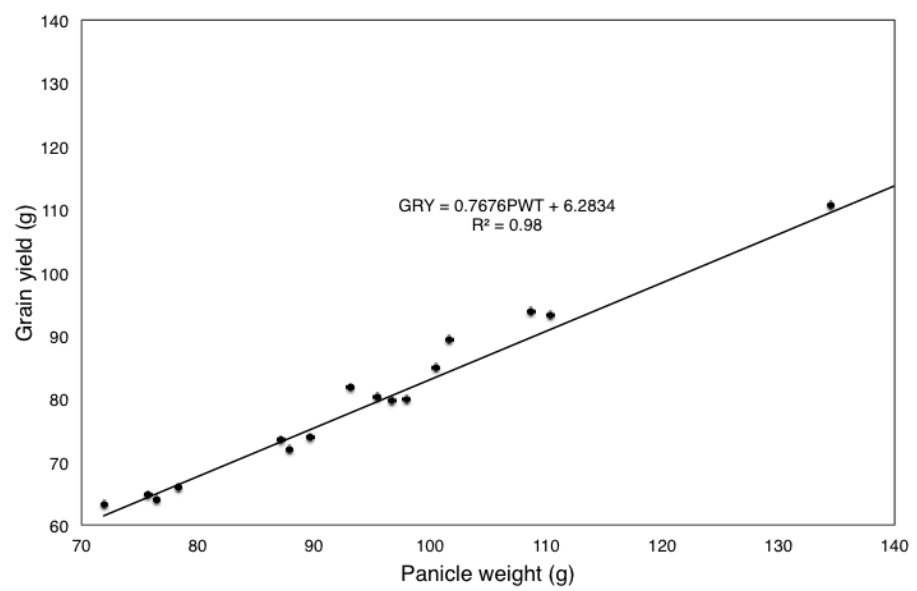

Fig 7. Relationship between panicle weight (PWT) and actual grain yield (GRY) from threshed panicles of diverse sorghum lines.

Table 7. Significant standard coefficient estimates (Beta values) from regression results of explanatory agro-morphological traits on panicle weight for diverse sorghum lines subjected to three irrigation schedules (Control; CTL, Pre-flowering; PRF, and Postflowering; PSF) pooled across two years.

\begin{tabular}{|c|c|c|c|}
\hline Panicle weight (g) & CTL & PRF & PSF \\
\hline Constant & -115.50 & -28.70 & -64.01 \\
\hline${ }^{\mathrm{F}} \mathrm{TBM}$ & ${ }^{\beta} 0.96$ & 0.90 & 0.87 \\
\hline SBM & 0.73 & 0.65 & 0.56 \\
\hline $\mathrm{pHI}$ & 0.52 & 0.56 & 0.49 \\
\hline PGL & 0.44 & 0.31 & 0.33 \\
\hline NGL & -0.50 & -0.47 & -0.38 \\
\hline PNL & 0.05 & -0.36 & -0.13 \\
\hline PWD & NS & -0.38 & -0.11 \\
\hline PNA & NS & 0.61 & 0.28 \\
\hline PDL & 0.03 & NS & 0.03 \\
\hline SDM & NS & NS & NS \\
\hline NOL & 0.14 & 0.05 & 0.08 \\
\hline HGT & NS & NS & NS \\
\hline BST & -0.02 & NS & -0.02 \\
\hline NDT & NS & NS & NS \\
\hline R-Squared & 0.97 & 0.94 & 0.95 \\
\hline Adjusted R-squared & 0.96 & 0.94 & 0.94 \\
\hline No. Observations & 1800 & 1628 & 1676 \\
\hline
\end{tabular}

${ }^{\mathrm{F}} \mathrm{TBM}$, total above ground biomass; SBM, above ground straw biomass; $\mathrm{pHI}$, panicle harvest index; PGL, percent green leaves; NGL, number of green leaves; PNL, panicle length; PWD, panicle width; PNA, panicle area; PDL, peduncle length; SDM, stem diameter; NOL, number of leaves; HGT, height; BST, basal tillers; and NDT, nodal tillers. "NS" not significant at $p \leq 0.05$. $\beta$ indicates Beta values of independent variables from standardized coefficients in regression analysis. 
value for $\mathrm{pHI}$ under the control treatment (CTL) was significantly lower than the pre-and postflowering treatments, which showed no significant difference in $\mathrm{pHI}$. While similar $\mathrm{pHI}$ values were observed under CTL in both years, $\mathrm{pHI}$ decreased by $19 \%$ and $17 \%$ from 2015 to 2016 under pre-and postflowering irrigation treatments respectively. In 2015, the number of green leaves (NGL) and the percent green leaves $(\mathrm{PGL})$ were highest under control irrigation treatment. Compared to the control values, NGL and PGL were similarly reduced by $57 \%$ and $32 \%$ under pre-and postflowering irrigation treatments respectively. In 2016, straw biomass (SBM) showed no significant difference between irrigation treatments. Genotypic distribution of total above ground dry biomass (TBM) and panicle weight (PWT) into quantiles showed some consistencies in both years, for lines in the $75 \%$ quartiles across irrigation treatments. In 2015 (Fig. 4), lines in the $75 \%$ quartiles for TBM under the three irrigation treatments were ranked as follows: 1 ) CTL irrigation (Fig. 4A, $\mathrm{TBM} \geq 195.0 \mathrm{~g})$; JB35, JB33, JB44, JB31, JB24, JB30, JB37, JB23, $J B 42$, Jb25, and JB34, 2) PRF irrigation (Fig. 4B; TBM $\geq 145.0 \mathrm{~g}$ ); JB25, JB24, JB35, JB33, JB31, JB30, BTx642, JB23, and JB42, and 3) PSF irrigation (Fig. 4C, TBM $\geq 150.0 \mathrm{~g}$ ); JB35, JB31, JB24, JB44, JB33, JB25, JB30, JB42, JB34, JB18, and JB23. Lines in the 75\% quartile for panicle weight under the three irrigation treatments ranked as follows: 1) CTL irrigation (Fig. 4A; PWT $\geq 99.5 \mathrm{~g})$; JB31, JB44, JB30, JB34, JB37, SC191, 2) PRF irrigation (Fig. 4B; PWT 79.0g); JB31, JB30, JB24, SC847, SC191, $\mathrm{JB} 44$, and JB17, and 3) PSF irrigation (Fig. 4C; PWT $\geq 88.0 \mathrm{~g}$ ); JB31, JB44, JB30, JB24, JB34, and JB18. In 2016 (Fig. 5), lines in the $75 \%$ quartiles for total biomass under the three irrigation treatments were ranked as follows: 1 ) Control irrigation (Fig. $5 A ; T B M \geq 100.0 \mathrm{~g})$; JB31, SC702, JB25, R.11259, and JB24, 2) PRF irrigation (Fig. 5B; TBM $\geq 74.0 \mathrm{~g}$ ); BTX378, JB31, JB24, JB39, R.11269, JB14, B1778, JB25, BTx3042, and TX7000, and 3) PSF irrigation (Fig. 5C; TBM $\geq 85.0$ ); JB31, B1778, BTx642, R.11259, JB25, JB24, SC110, and JB14. Lines in the 75\% quartile for panicle weight under the three irrigation treatments were ranked as follows: 1) CTL irrigation (Fig. 5A; PWT $\geq 54.0$ g); JB31, JB25, TX7000, JB24, BTx3042, R.11259, and SC191, 2) PRF irrigation (Fig. 5B; PWT $\geq 40.0 \mathrm{~g}$ ); BTx3942, BTx378, JB39, SC191, R.11269, B1778, and SC270, and 3) PSF irrigation (Fig. 3C; $\mathrm{PWT} \geq 44.0 \mathrm{~g})$; JB31, B1778, BTx642, JB25, R.11259, and SC191. The staygreen traits, number of green leaves (NGL) and percent green leaves (PGL) were evaluated only in 2015, and showed similar trends in genotypic variation across treatments (Fig. 6). Lines in the $75 \%$ quartile for PGL under the three irrigation treatments were ranked as follows: 1) CTL irrigation (Fig. 6A; PGL $\geq 60 \%$ ); JB37, JB34, JB25, JB42, JB44, JB18, BTX642, JB23, JB30, and JB24, 2) PRF irrigation (Fig. 6B; PGL $\geq 33 \%$ ); BTx642, JB25, JB26, JB35, JB14, JB33, and JB23, and 3) PSF irrigation (Fig. 6C; PGL $\geq 40 \%$ ); BTx642, JB33, JB26, JB25, JB14, JB24, JB15, and JB19.

\section{Relationships between assessed agro-morphological characteristics}

To evaluate the relationships between assessed parameters (traits), Pearson correlations were performed across irrigation treatments for both years. Yield performance was evaluated based on panicle weight following a tight fit correlation $(r=0.98, p \leq 0.05)$ between actual grain yield and panicle weight of 21 randomly selected and thrashed panicles across treatments in both years (Fig. 7). Tesso et al. (2011) found a $91 \%$ correlation between panicle weight and grain yield working on 200 sorghum accessions from Ethiopia.

Relations between panicle weights (PWT) to some assessed parameters showed similar trends in significance and magnitude across likely irrigation treatments in both years (Table 6). Panicle weight showed strong positive correlations $(r>0.70)$ to total biomass (TBM), panicle width (PWD), and panicle area (PNA) irrespective of irrigation treatment and year. The relations between PWT to panicle harvest index $(\mathrm{pHI})$ and panicle length (PNL) though significant across treatments, were stronger in 2016 than 2015. Relations between peduncle length (PDL) and PWT were negative across all irrigation treatment in 2015 and the control irrigation treatment (CTL) in 2016, but non-significant for the pre-and postflowering irrigation treatments in 2016. Plant height (HGT) and stem diameter (SDM) were positively related to panicle weight, though weaker relations ( $r=0.19)$ were observed for HGT under pre-flowering irrigation treatment in both years. While the number of leaves (NOL) showed positive relations to panicle weight in 2015, the relations of NOL to PWT were insignificant or slightly negative (under PRF) in 2016. The number of basal tillers (BST) was not a determining factor to panicle weight. Nodal tillers (NDT) negatively affected PWT under pre-and postflowering irrigation treatments in 2016.

To further evaluate the estimated contribution of each of the assessed agro-morphological traits to the prediction of grain yield (represented as panicle weight), a multiple regression analysis was performed across irrigation treatments, with panicle weight as the dependent variable to the other predicting variables (Table 7). Since the relations between panicle weight and the other assessed parameters were similar across irrigation treatments and years (see table 6), data were pooled.

Together, the other assessed parameters predicted panicle weight by more than $94 \%$ with adjusted R-squared values of 0.97, 0.94, and 0.95 under CTL, PRF, and PSF irrigation treatments respectively. Based on observed Beta values, total biomass (TBM), straw biomass (SBM), panicle harvest index $(\mathrm{pHI})$, percent green leaves (PGL), and panicle area (PNA); each made strong unique positive contribution to PWT irrespective of irrigation treatment. On the other hand, number of green leaves (NGL), panicle length (PNL), and panicle width (PWD); each made negative contributions to explaining panicle weight; more so under pre-flowering than under postflowering irrigation treatment. While an increase in the number of leaves and the peduncle exertion explained a small positive contribution to PWT, increase in basal tillers had the opposite effect under postflowering irrigation. Plant height and nodal tillers showed no significant effect in predicting panicle weight.

\section{Discussion}

Plants subjected to soil water deficit often exhibit agronomic, morphological, physiological, and biochemical modifications such as decrease growth and elongation, decrease stomatal 
conductance, photosynthesis, changes in hormonal and enzyme activities, and transpiration rates (Ripley et al., 2007; Jiang and Zhang, 2002; Pinheiro and Chaves, 2011), which inevitably lead to yield reductions. Sorghum is considered to be better adapted to drought than most other crops (Ludlow and Muchow, 1990; Sanchez et al., 2002), and sorghum has genetic variability for pre-and postflowering drought tolerance and related traits (Rosenow and Clark, 1982; Rosenow et al., 1996, Burke et al., 2013, Tuinstra et al., 1998, Borrell et al., 1999, Harris et al., 2007, Emendack et al., 2017). Generally, genetic improvement of crops for drought tolerance requires a search for possible relationship between agronomic, morphologic, and physiological traits with grain yield (Quarrie et al., 1999). The interrelationships between these quantitatively inherited plant traits and their direct or indirect contribution on grain yield is of great importance for success in selections conducted in breeding programs (Abinasa et al., 2011).

The parental stay-green donor sorghum line used in most breeding program is BTX642 (also know as B35), which is a durra sorghum from Ethiopia (Rosenow et al., 1983). It is the best-characterized source of stay-green in sorghum and appears to have the Type A stay-green, which is related to the delay in onset of leaf senescence (Thomas and Howard, 2000; Thomas and Smart, 1993). While BTX642 has good combine agronomics; three dwarf and semi open panicle, its smaller panicle size, late maturity, and lower grain yields under ideal conditions may be drawback traits that limit its utilization in sorghum breeding programs. The current research aim at identifying other sources of pre-and/or postflowering drought tolerance from a diverse group of sorghum lines, by identifying and characterizing agro-morphological traits that may be related to yield stability under drought conditions imposed before flowering (pre-flowering, PRF) and after flowering/anthesis (postflowering, PSF).

In the current study, observed variations in the assessed agro-morphological traits were largely due to genotypic differences and irrigation treatments. Most of the assessed parameters (except the number of leaves, panicle length, and stem diameter) showed decreases in values from 2015 to 2016 across similar irrigation treatments. These decreases can be explain by: 1$)$ the suboptimal temperature dips $\left(4^{\circ} \mathrm{C}\right.$ on average) observed at the beginning and midseason of the 2016 season $\left(23.8^{\circ} \mathrm{C}\right.$ average seasonal temperature) compared to the optimal temperatures $\left(27.6^{\circ} \mathrm{C}\right.$ average seasonal temperature) in the 2015 season. Suboptimal temperatures have been shown to reduce growth and development (Angus et al., 1981), which may affect biomass accumulation and thus impact yield. AND 2) the lower total irrigation applied in 2016 compared to 2015. This may have subjected 2016 plants into an earlier and even stronger water deficit. A combination of temperature and water stress only exacerbates these effects. The unresponsiveness of panicle length, leaf number, and stem diameter to irrigation treatments and environmental variability, indicate that these traits are highly heritable in sorghum. Researching on postflowering drought tolerance in Eritrean landraces, Tesfamichael et al. (2015) recorded the highest heritability for panicle length and leaf number; moderate heritability for grain yield, biomass, harvest index, peduncle length, and productive tillers; and lowest heritability in panicle width and stay-green score.

Drought tolerance is defined as the relative yield of a genotype compared with other genotypes subjected to the same drought stress (Hall, 1993), while the drought susceptibility of a genotype is measured as a reduction in yield under drought stress (Blum et al., 1988). The current research evaluated drought tolerance based on panicle weight; its' relations to the other assessed agro-morphological traits, and its' variability as predicted by each individual trait under imposed pre-flowering and postflowering drought treatment, compared to the well-watered treatment. Total above ground biomass (TBM), straw biomass (SBM), panicle harvest index $(\mathrm{pHI})$, and percent green leaves (PGL; stay-green) were identified as strong predictors (TBM being the strongest predictor) for panicle weight across irrigation treatments. Additionally, panicle area and panicle width were also identified as a positive predictors to panicle weight under both pre-flowering and postflowering drought stress.

Breeding for drought tolerance involves combining good yield potential in optimum conditions and selecting high heritable traits related to drought tolerance (Bennani et al., 2016).

Under the control irrigation treatment, some converted lines performed better than the standard or common staygreen donor lines. While most of the assessed parameters were positively related to panicle weight, some of the JB lines performed better than most of the common breeding lines for the strong yield predicting traits. The mostly tall JB lines 17,18 , $23,25,30,34,37,42$, and 44 produced more biomass and heavier panicles (see supplementary table 1 ), though the percent green leaves (staygreen) was similar to BTX642. From the above lines, only JB30 was ranked in the top $75 \%$ quartile for panicle harvest index, suggesting that the staygreen trait may not always be an important contributor to yield under well-watered environments. Numerous researches (Henzell and Gillieron, 1973; Duncan et al., 1981; Rosenow et al., 1983; Tangpremsri, 1989) suggested that staygreen might be correlated with low grain yield. However, Borrell et al. (2014) did not find any consistent yield cost associated with the staygreen quantitative trait loci (QTLs) under irrigated conditions. Earlier studies did show little or no yield penalty associated with the BTX642 source of staygreen under highyielding conditions (Kassahun et al., 2010, Vadez et al., 2011). Blum (2011) stated that the expression effects of staygreen to yield become more prominent under severe drought conditions.

The application of drought stress during pre-flowering growth can have the largest impact on grain yield as it is the longest state of development, and water stress can result in reduced panicle size and grain numbers, leaf rolling, leaf tip burn, delayed flowering, poor panicle exertion, and panicle blasting (Rosenow et al., 1996). While the physiological basis of pre-flowering drought stress (PRF) is not well know, preflowering drought tolerance has been evaluated and related to numerous phenotypic characteristics. Some common sources of pre-flowering drought tolerance include TX7000, and BTx623. In the current study, converted lines JB39, SC270, SC191, and recombinant inbred line R.11269 all exhibited 
greater panicle area (or panicle size), heavier panicle, and lesser percent reductions in panicle weight than TX7000 and BTx623. Though the relation between panicle weight and staygreen (PGL) under PRF in 2015 was insignificant, staygreen and panicle area as stand-alone traits were positive contributors in predicting panicle weight (grain yield) under PRF. Lines JB33 and JB35 were ranked in the top $75 \%$ quartile in both traits, making them additional plausible candidates lines for preflowering drought stress tolerance. However, JB33 saw a drastic reduction (80\%) in panicle weight compared to JB35 (32\%), SC270 (22\%), SC191 (22\%), JB39 (3\%), R.11269 (3\%), and senescent lines TX7000 (39\%) and BTx623 (45\%). This confirms the staygreen trait as a non-reliable tool in selection for pre-flowering drought resistance.

Most of the commercial sorghum hybrids grown under nonirrigated conditions in the United States have considerable pre-flowering drought resistance but not postflowering drought resistance (Xu et al., 2000). The most damaging drought stress is that which occurs during the post-flowering stage of crop growth (Kassahun et al., 2010). The staygreen trait is the best-characterized form of postflowering drought tolerance in sorghum. Variation in the staygreen trait has been predictive of hybrid grain yield performance in drought-prone Australian sorghum production environments (Jordan et al., 2012; Borrell et al., 1999, 2000b). In the current research, in addition to above ground biomass, panicle harvest index, and panicle area; percent green leaves (staygreen) was also a strong predictor for panicle weight under postflowering drought stress. Evaluation of percent green leaves under postanthesis drought in 2015, ranked in descending order BTx642, JB33, JB26, JB25, JB14, JB24, JB15, and JB19 in the top 75\% percentile. Percent green leaves values ranged from $40-66 \%$, with BTX642 (66\%) and JB33 (61\%) having the highest values. Mahalakshimi and Bidinger (2002) found percent green leaves area values range of $19-64.7 \%$ at 45 days after flowering while working with ICRISAT staygreen germplasm under terminal stress conditions. They actually calculated a percent green leaf area of 62.7 for BTx642 compared to $66 \%$ calculated in the current study. Kassahun et al. (2010) working with staygreen introgression lines and BTX642, found none of the lines achieved the same level of staygreen as BTX642. Compared to BTx642, under post-anthesis drought, panicle weights values were higher in JB24 and JB33, similar in JB14 and JB25, and lower in JB15, JB19, JB22, and JB26. However, the reductions in panicle weight by terminal stress were less in JB24 (3\%), similar in JB14 (11\%), and higher in JB19 (20\%), JB22 (19\%), JB33 (23\%), JB25 (24\%), and JB15 (33\%), when compared to BTX642 (9\%). Thus, staying green was not always a guarantee to yield stability under post-anthesis water stress. Comparatively, reduction in panicle weight by post-anthesis stress was $47 \%$ in known senescent line TX7000.

This research identifies other sources of pre-flowering and postflowering drought tolerance that could be use by breeding programs for introgression into elite sorghum lines. The lines JB39, SC191, and SC270 and RIL R.11269 are plausible sources for pre-flowering drought tolerance while JB14, JB15, JB19, JB22, JB24, JB25, JB26, and JB33 are sources for the staygreen trait. Staygreen has been shown to improve and stabilize yield under moisture stress conditions (Tao et al., 2000), but it also reduces the source-sink translocation from leaves to grain (Amelework et al., 2015). While the staygreen trait is a good selection tool for postflowering drought tolerance, identifying staygreen lines with minimal reductions in grain yield by postflowering water deficit, and earlier flowering dates, will ensure that grain yield is not over sacrificed by the ability of the crop to stay green under terminal drought conditions.

\section{Materials and methods}

\section{Plant materials and experimental design}

A total of 54 diverse sorghum lines were evaluated in this study include: introgression sorghum lines from Ethiopia (denoted JB for John Burke, USDA-ARS, Lubbock, Texas), select lines from the sorghum conversion panel (denoted SC), and breeding lines developed by the USDA-ARS Lubbock sorghum breeding program (Table 1 ).

Lines were evaluated for pre-and postflowering drought tolerance during 2015 and 2016 growing seasons in the Amarillo fine sandy loam soil of Lubbock, Texas. Sorghum seeds from 55 lines were planted at $3 \mathrm{~cm}$ depth using a modified John Deere MaxEmerge Planter. Single-row plots, $4.6 \mathrm{~m}$ in length, $1.0 \mathrm{~m}$ row spacing and $3-4 \mathrm{~cm}$ plant spacing where planted with 60 seeds, with three replications per line in three treatment blocks in a randomized complete block design. Either side of each irrigation block was planted with two rows of a commercial hybrid to minimize edge effects on boarder plots. Lines were categorized into three groups (status) reflecting if they were introgress, converted, or standard/commonly used breeding lines. The lines were selected either for their known stay-green (postflowering trait), senescence, or dhurrin levels determined from mature leaves of plants in the late vegetative stage. Burke et al., 2013 characterized matured leaf dhurrin content as a quantitative measure of the level of pre-and postflowering drought tolerance in sorghum.

The JB lines were developed because the Ethiopian lines used in the development of JB lines maintained green leaves ( $\mathrm{a}$ stay-green trait) at the lower levels of the canopy under low light condition. The sorghum conversion lines (SC) were selected based on their dhurrin levels by Hayes et al. 2015 (high; SC1154-14E, SC335, SC54, SC56, SC599, and SC110, low; SC191, SC270, SC774, and SC1506). SC1506 is also a determined senescent line. The remaining breeding lines were used in the USDA-ARS Lubbock sorghum breeding programs with known pre-and postflowering characteristics (stay-green or senescence) and/or dhurrin levels (high or low). BTx642 (also know as B35; an elite staygreen and postflowering drought tolerant; Harris, 2007), B1778, and B4R are standard high dhurrin lines used for the breeding and evaluation of the stay-green trait. TX7000 (pre-flowering drought resistant and postflowering drought tolerant; $X u$ et al., 2000), BTx623, BTx378, RTx430 are standard or common senescent and low dhurrin lines also used in breeding programs. R9188 is a high dhurrin line. R.11259 and R.11269 are inbred lines developed within the USDA-ARS Lubbock breeding program with high dhurrin levels. In 2015, the experiment was planted on June $1^{\text {st }}$, at the research field of the Plant Stress and Germplasm 
Development Research (PSGD) Unit of USDA-ARS, in Lubbock, Texas. Three subsurface drip irrigation (SDI) treatments were used, viz. 1) Control (CTL) irrigation; with continuous irrigation of $5 \mathrm{~mm} /$ day from planting to physiological maturity, 2) Preflowering (PRF) irrigation; irrigation $(5 \mathrm{~mm} /$ day) applied from planting till the booting developmental stage and then withheld till physiological maturity, and 3) Postflowering (PSF) irrigation; irrigation $(5 \mathrm{~mm} /$ day) applied from planting till anthesis and then withheld till physiological maturity. Following evaluation from the 2015 season, lines with distinguished pre-and postflowering characteristics (stay-green or senescence) with additional standard/common breeding lines used in breeding programs for stay-green and dhurrin level evaluations were planted in 2016. Seeds were sown on May $27^{\text {th }}$ at the Research fields of Texas AgriLife Research and Extension Center (TAES), in New Deal, Texas, with furrow irrigation system. The TAES field is located 9 miles north of the PSGD fields. Similar experimental design with three irrigation treatments was used.

\section{Imposing drought treatments}

The latest recommended planting dates for sorghum in Lubbock county located in West Texas ranges from June $15^{\text {th }}$ for late maturity lines, to July $10^{\text {th }}$ for early maturity lines or hybrids (United Sorghum Checkoff Program). In 2015, drought stress was imposed on July $17^{\text {th }}$ ( 47 days after planting; DAP) on the PRF irrigation treatment by discontinuing irrigation when at least $50 \%$ field booting was attained. Irrigation was continuously withheld till physiological maturity. Drought was later imposed on July $30^{\text {th }}$ (60 DAP) on the postflowering irrigation treatment by withholding irrigation when at least $50 \%$ field flowering was attained. No further irrigation was applied. Continuous daily irrigation of $5 \mathrm{~mm}$ was supplied to the control treatment 3 weeks after planting until physiological maturity.

In 2016, furrow irrigation was applied per treatment as follows: 1) Irrigation applied on June $27^{\text {th }}$ to all treatments (30 DAP), 2) Irrigation applied on July $18^{\text {th }}$ to control and postflowering treatments (pre-flowering stress imposed 52 DAP), and 3 ) Irrigation applied on August $2^{\text {nd }}$ on control treatment only (postflowering stress imposed 67 DAP).

\section{Traits measured}

At physiological maturity, 10 randomly selected plants were harvested from the inner $3.6 \mathrm{~m}$ (to eliminate edge and saddleback effects) of each replicated plot for sampling of agromorphological characteristics. Characteristics were divided into 2 categories viz. 1) Morphological characters such as plant height (HGT) from base of plant to tip of panicle; number of leaves (NOL); number of green leaves (NGL); percent green leaves (PGL), number of green leaves as a percentage of number of leaves; number of basal tillers (BST); number of nodal (asynchronous) tillers (NDT); Stem diameter (SDM) at $30 \mathrm{~cm}$ above ground; peduncle length or exertion (PDL) from ear of flag leaf to base of panicle; panicle length (PNL) from base to tip of panicle; panicle width (PWD) measured on the widest section of the panicle, AND 2) Yield-related characters such as above ground straw dry biomass (SBM), excluding dried panicle; total above ground dry biomass (TBM), including dried panicle; panicle weight (PWT), weight of dried panicle; and panicle harvest index $(\mathrm{pHI})$, the ratio PWT:TDB. Panicle weight was used instead of actual thrashed grain yield based on a $98 \%$ correlation between panicle weight and threshed grain yields from 21 randomly selected and thrashed panicles (see figure 7). The stay-green characteristic was evaluated 10 days prior physiological maturity by: 1) visual rating of leaf plant death on a scale of 1-5; with 1 implying plant is completely green, and 5 meaning plant has completely senesced and 2) percent green leaves. Based on an $81 \%$ correlation between visual leaf plant dead ratings and percent green leaves (see supplementary figure 1), the percent green leaves parameter was used to evaluate stay-green. All plant materials were dried for at least 96 hours in a walk-in Gruenberg oven set at $65^{\circ} \mathrm{C}$ for dry weight calculations.

\section{Statistical Analysis}

Data were analyzed using SPSS 18.0 (SPSS Inc., USA) and JMP 12 (SAS Institute). Data set was initially subjected to principal component analysis to explore strong patterns, identify any variations, and explain any variance or covariance in the assessed agro-morphological characteristics due to the different seasonal irrigation treatments. Multivariate analysis of variance was used to identify significant interactions of treatments (year, irrigation treatment, status, and genotypes) on assessed characteristics based on Wilk's Lamda test and it associated significant level expressed in relative partial Eta squared $\left(\eta^{2}\right)$. Partial $\eta^{2}$ represents the proportion of the variance in the dependent variable(s) that can be explained by the independent variable(s). Using Cohen, 1988, $\eta^{2} \leq 1 \%$ is considered small effect; $0.01 \leq \eta^{2} \leq 6 \%$ is considered medium effect; and $\eta^{2} \geq 14 \%$ is considered a large effect. The Bonferoni adjustment was applied where necessary to avoid type I errors. Tukey's honest significant difference (HSD) test separated means for agro-morphological characteristics. To identify top performers for a particular trait, a statistical distribution was done categorizing outcomes into the $75 \%$, $50 \%, 25 \%$, and less than $25 \%$ quartiles. Pearson correlation matrix was used to identify correlations between parameters. Observed trends in ranking of genotypes were based on TukeyKramer HSD connecting letters ranking report for the assessed characteristic. Significance was stated at $p \leq 0.05$ or $p \leq 0.01$ where applicable. Percent green leaves characteristics were transformed using the arcsine function prior to statistical analysis to minimize the effect of heterogeneity of error variances. Beta values from standardized coefficients of multiple regression analysis were used to ascertain the estimated contribution of each assessed agro-morphological trait to the variability of grain yield; determined as panicle weight.

\section{Conclusion}

The current research evaluated drought tolerance based on panicle weight (as a reliable alternative to grain yield); its' relations to other assessed agro-morphological traits, and its' 
variability as predicted by each individual trait under imposed pre-flowering and postflowering drought treatments, compared to the well-watered treatment. Total above ground biomass (TBM), straw biomass (SBM), panicle harvest index $(\mathrm{pHI})$, and percent green leaves (PGL; staygreen) were identified as strong predictors (TBM being the strongest predictor) for panicle weight across the irrigation treatments. Additionally, panicle area was also identified as a positive predictor to panicle weight under both pre-flowering and postflowering drought stress. The lines JB39, SC191, and SC270 and RIL R.11269 were identified as other plausible sources for pre-flowering drought tolerance, while JB14, JB15, JB19, JB22, JB24, JB25, JB26, and JB33 were also identified as other sources for the staygreen trait, with shorter days to flowering and heavier panicle than the standard staygreen line BTx642 under ideal conditions.

\section{Acknowledgment}

The authors would like to thank student aides Ms. Caroline Kelly and Ms. Lupita Martinez for their help in data collection and plant processing. The authors also acknowledge the support of the U.S. Sorghum Checkoff Program.

\section{Disclaimer Statement}

Mention of trade names or commercial products in this publication is solely for the purpose of providing specific information and does not imply recommendation or endorsement by the U.S. Department of Agriculture. USDA is an equal opportunity provider and employer.

\section{References}

Abinasa M, Ayana A, Bultosa G (2011) Genetic variability, heritability and trait associations in durum wheat (Triticum turgidum L. var. durum) genotypes. African J Agric Res. 6(17):3972-3979.

Ahmad SQ, Khan S, Ghaffar M, Ahmad F (2011) Genetic diversity for yield and other parameters in maize genotypes. Asian J Agric Sci. 3:385-388.

Amelework B, Shimelis H, Tongoona P, Laing M (2015) Physiological mechanisms of drought tolerance in sorghum, genetic basis and breeding methods: A review Afric J Agric Res. 10(31):3029-3040.

Angus JF, Cunningham RB, Moncure MW, Mackenzie DH (1981) Phasic development in field crops. I. Thermal response in the seedling phase. Field Crops Res. 3:365-378.

Bennani S, Ahmed B, Naserelhaq N, Mohammed J, Hassan O (2016) Efficiency of selection indices in screening bread wheat lines combining drought tolerance and high yield potential. J Plant Breed Crop Sci. 8(5):72-86.

Blum A (2011) Plant breeding for water-limited environments. Berlin: Springer.

Blum A, Mayer J, Golan G (1988) Agronomic and physiological assessments of genotypic variation for drought resistance in sorghum. Austr J Agric Res. 40:49-61.
Borrell AK, Douglas ACL (1997) Maintaining green leaf area in grain sorghum increase nitrogen uptake under post-anthesis drought. Inter Sorghum Millet Newsl. 38:89-92.

Borrell AK, Bidinger FR, Sunitha K (1999) Stay-green trait associated with yield in recombinant inbred sorghum lines varying in rate of leaf senescence. Int Sorghum Millet Newsl. 40:31-34.

Borrell AK, Hammer GL, Henzell RG (2000b) Does maintaining green leaf area in sorghum improves yield under drought? II. Dry matter production and yield. Crop Sci. 40:1037-1048.

Borrell AK, Oosterom EJV, Hammer GL, Jordan DR, Douglas A (2003) The physiology of stay-green in sorghum. Proceeding of the $11^{\text {th }}$ Australian Agronomy Conference. http://www.regional.org.au/au/asa/2003/c/i/borrell.htm

Borrell AK, Jordan DR, Mullet JE, Henzell RG, Hammer G (2006) Drought adaptation in sorghum. J-M Ribaut (Ed). Drought adaptation in cereals, Haworth Press Inc., New York (2006):335-339.

Borrell AK, Oosterom EJV, Mullet JE, George-Jaeggli B, Jordan DR, Klein PE, Hammer GL (2014) Stay-green alleles individually enhance grain yield in sorghum under drought by modifying canopy development and water uptake patterns. New Physiologist. doi:10.1111/nph.12869

Burke JJ, Chen J, Burow GB, Mercherf Y, Rosenow DT, Payton P (2013) Leaf dhurrin content is a quantitative measure of the level of pre- and postflowering drought tolerance in sorghum. Crop Sci. 53:1056-1065.

Cohen J (1988) Statistical power analysis for the behavioral sciences. Hillsdale, NJ: Erlbaum.

Cuevas HE, Prom LK, Isakeit T, Radwan G (2016) Assessment of sorghum germplasm from Burkina Faso and South Africa to identify new sources of resistance to grain mold and anthracnose. Crop Protect. 79:43-50.

Dogget $H$ (1988) Sorghum, $2^{\text {nd }}$ edition. Longman.

Duncan RR, Bockholt AJ, Miller FR (1981) Descriptive comparison of senescent and non-senescent sorghum genotypes. Agron J. 73:849-853.

Emendack YY (2007) Drought performance in millet (Panicum miliaceum) and sorghum (Sorghum bicolor L. Moench). www.dissertation.de. ISBN: 978-3-86624-231-9.

Emendack YY, Burke JJ, Hayes CM, Burow GB, Sanchez J, Chopra R, Xin Z (2016) Early seedling growth characteristics relates to the staygreen trait and dhurrin levels in sorghum. Crop Sci. 57:1-12.

Hall AE (1993) Is dehydration tolerance relevant to genotypic differences in leaf senescence and crop adaptation to dry environments. In. Close TJ and EA Bray, Eds., Plant responses to cellular dehydration during environmental stress, 1-10.

Hamza NB, Idris AE, Elmunsor II, Ibrahim AIA, Abuali AI (2016) Drought tolerance assessment in grain sorghum genotypes using agro-morphological traits and DNA markers. Int. J Plant Breed and Gen. 10:125-131.

Harris K, Subudhi PK, Borrell AK, Jordan DR, Rosenow DT, Nguyen $\mathrm{H}$ et al (2007) Sorghum stay-green QTL individually reduce postflowering drought-induced leaf senescence. J Exp Bot. 58:327-338. 
Hayes CM, Burow GB, Brown JB, Thurber C, Xin Z, Burke JJ (2015) Natural variation in synthesis and catabolism genes influences dhurrin content in sorghum. Plant Genome 8. doi:10.3835/plantgenome2014.09.0048

Henzell RG, Gillieron W (1973) Effects of partial and complete panicle removal on the rate of death of some Sorghum bicolor genotypes under moisture stress. Queensland. Agric and Anim Sci. 30:291-299.

Jiang M, Zhang J (2002) Water stress-induced abscisic acid accumulation triggers the increased generation of reactive oxygen species and up-regulates the activities of antioxidant enzymes in maize leaves. J Exp Bot. 53(379): 2401-2410.

Jordan DR, Hunt $\mathrm{CH}$, Cruickshank AW, Borrell AK, Henzell RG (2012) The relationship between the stay-green trait and grain yield in elite sorghum hybrids grown in a range of environments. Crop Sci. 52:1153-1161.

Kassahun B, Bidinger FR, Hash CT, Kuruvinashett MS (2010) Stay-green expression in early generation sorghum QTL introgression lines. Euphytica 172:351-362.

Ludlow MM, Muchow RC (1990) A critical evaluation of traits for improving crop yields in water-limited environments. Adv Agron. 43:107-153.

Mahalakshimi V, Bidinger FR (2002) Evaluation of stay-green sorghum germplasm lines at ICRISAT. Crop Sci. 42:965-974.

Mitra J (2001) Genetics and genetic improvement of drought resistance in crop plants. Current Sci. 80:758-763.

Mollasadeghi V, Imani AA, Shahryari R, Khayatnezhad M (2011) Classifying bread wheat genotypes by multivariable statistical analysis to achieve high yield under after anthesis drought. Middle-East J Sci Res. (72):217-220.

Mullet JE, Klein RR, Klein PE (2001) Sorghum bicolor-an important species for comparative grass genomics and a source of beneficial genes for agriculture. Current opinion in Plant Biol. 5:118-121.

Pinheiro C, Chaves MM (2011) Photosynthesis and drought: can we make metabolic connections from available data? J Exp Bot. 62(3):869-882.

Prom LK, Erpelding JE (2009) New sources of grain mold resistance among sorghum accessions from Sudan. Trop Subtrop Agroecosyst. 10(3):457-463.

Quarrie SA, Lazic-Jancic V, Kovacevic, Steed A, Pekic S (1999) Bulk segregant analysis with molecular markers and its use for improving drought resistance in maize. J Exp Bot. 50:1299-1306.

Rao SS, Seetharama N, Kiran Kumar KA, Vanderlip RL (2004) Characterizing phenology and growth stages of sorghum hybrids. NTCS Bulletin series no.14. National Research Center for Sorghum, Rajendranagar, Hyderabad, India.pp.20

Ripley BS, Gilbert ME, Ibrahim GD, Osborne CP (2007) Drought constraints C4 photosynthesis: stomatal and metabolic limitations in C3 and C4 subspecies of Alloteropsis semialata. J Exp Bot. 58:1351-1363.

Rosenow DT, Quinsenberry JE, Wendt CW, Clark LE (1983) Drought tolerant sorghum and cotton germplasm. Agric Water Manage. 7:207-222.
Rosenow DT, Clark LE (1995) Drought and lodging resistance for a quality sorghum crop. In. Proceeding of the $50^{\text {th }}$ Annual Corn and Sorghum Industry research Conference. Chicago, IL, 82-97.

Rosenow DT, Ejeta G, Clark LE, Gilbert ML, Henzell RG, Borrell $A K$, et al (1996) Breeding for pre-and postflowering drought stress resistance in sorghum. In: D Rosenow, editor, The international conference on genetic improvement for sorghum and millet. INTSORMIL, Lubbock, TX. P. 400-424.

Sanchez AC, Subudhi PK, Rosenow DT, Nguyen HT (2002) Mapping QTLs associated with drought resistance in sorghum. Plant Mol Biol. 48:713-726.

SAS Institute. 2014. JMP. Release 11.0. SAS Inst., Cary, NC.

SPSS. 2009. SPSS Statistics for windows. Release 18.0. SPSS Inc., Chicago, IL.

Tangpremsri T (1989) Physiological studies on the performance of sorghum genotypes under moisture limiting conditions. Brisbane, Australia: University of Queensland.

Tao YZ, Henzell RG, DJordan DR, Butler DG, Kelly AM, McIntyre $\mathrm{CL}$ (2000) Identification of genomic regions associated with staygreen in sorghum by testing RILs in multiple environments. Theor Appl Genet. 100:1225-1232.

Tesfamichael A, Githiri S, Kasili R, Woldeamlak A, Nyende AB (2015) Genetic variation among sorghum landraces from Eritrea under postflowering drought stress conditions. Amer. J Plant Sci. 6:1410-1424.

Teso T, Tirfesa A, Mohammed H (2011) Association between morphological traits and yield components in the durra sorghum of Ethiopia. Hereditas 148:98-109.

Thomas H, Howard CJ (2000) Five ways to stay green. J Exp Bot. 51:329-337.

Thomas H, Smart CM (1993) Crops that stay green. Ann Appl Biol. 123:193-219.

Tuinstra MR, Grote EM, Goldsborough PB, Ejeta G (1997) Genetic analysis of postflowering drought tolerance and components of grain development in Sorghum bicolor (L.) Moench. Mol Breeding. 3:439-448.

Tuinstra MR, Ejeta G, Goldsbrough PB (1998) Evaluation of near-isogenic sorghum lines contrasting for QTL markers associated with drought tolerance. Crop Sci. 38:835-842.

Upadahyaya HD, Pundir RPS, Dwevdi SI, Gowda CLL, Reddy VG, Singh S (2009) Developing a mini core collection of sorghum for diversified utilization of germplasm. Crop Sci. 49:17691780.

Vadez V., Deshpande SP, Kholova J, Hammer GL, Borrell AK, Talwar HS, Hash CT (2011) Stay-green quantitative trait loci's effects on water extraction, transpiration efficiency and seed yield depend on recipient parent background. Funct Plant Biol. 38:553-566.

Xu WW, Subufhi PK, Crasta OR, Rosenow DT, Mullet JE, Nguyen HT (2000) Molecular mapping of QTLs conferring stay-green in grain sorghum. Genome 43:461-469.

Yordanov I, Velikova V, Tsonev T (2003) Plant responses to drought and stress tolerance. Bulg J Plant Physiol., Special Issue, 187-206.

Zadoks JC, Chang TT, Konzak CF (1974) A decimal code for the growth stage of cereals. Weed Res. 14:415-421. 